\title{
BMJ Open Radiation protection effect of mobile shield barrier for the medical personnel during endoscopic retrograde cholangiopancreatography: a quasi- experimental prospective study
}

Kwang Hyun Chung, ${ }^{\ominus}$ Young Sook Park, Sang Bong Ahn, Byoung Kwan Son ${ }^{\odot}$

To cite: Chung KH, Park YS, Ahn SB, et al. Radiation protection effect of mobile shield barrier for the medical personne during endoscopic retrograde cholangiopancreatography: a quasi-experimental prospective study. BMJ Open 2019;9:e027729. doi:10.1136/ bmjopen-2018-027729

- Prepublication history for this paper is available online. To view these files, please visit the journal online (http://dx.doi. org/10.1136/bmjopen-2018027729).

Received 19 November 2018 Revised 11 January 2019 Accepted 7 February 2019
Check for updates

(C) Author(s) (or their employer(s)) 2019. Re-use permitted under CC BY-NC. No commercial re-use. See rights and permissions. Published by BMJ.

Department of Internal Medicine, Eulji General Hospital, Eulji University School of Medicine, Seoul, Republic of Korea

Correspondence to Professor Byoung Kwan Son; sbk1026@eulji.ac.kr

\section{ABSTRACT}

Objective To investigate the effectiveness of radiation protection offered by a newly designed mobile shield barrier for medical personnel during endoscopic retrograde cholangiopancreatography (ERCP).

Design Quasi-experimental prospective study. Setting ERCP procedures conducted between October 2016 and June 2017 at a single secondary referral hospital that performs approximately 250 therapeutic ERCP procedures annually.

Interventions The mobile shield barrier was a custommade $2 \mathrm{~mm} \mathrm{~Pb}$ shielding plate (width: $120 \mathrm{~cm}$, height: $190 \mathrm{~cm}$ ) with a $0.5 \mathrm{~mm} \mathrm{~Pb}$ window (width: $115 \mathrm{~cm}$, height: $60 \mathrm{~cm}$ ) on its upper part was used. Four wheels were attached to the bottom to allow easy moving.

Primary and secondary outcome measures The radiation doses were measured during ERCP using personal thermoluminescence dosimetry (TLD) badges on both sides of the mobile shield barrier (patient's side: TLD1 and medical staff's side: TLD2). The radiation doses were also measured on the outer surface of the thyroid shield of the endoscopist (TLD3), and on the chest area inside the protective apron of the endoscopist (TLD4) and the main assistant (TLD5). The TLD was changed and reported once every 3 months. The radiation dose measured by TLD badges were compared.

Results During the study period, a total of 128 ERCP procedures were performed. The mean fluoroscopy time per procedure was $244.9 \pm 257.0 \mathrm{~s}$ and the mean number of digital radiographs per procedure was $3.7 \pm 1.0$. TLD1 (outside the barrier) had a mean radiation dose of $26.85 \pm 3.47 \mathrm{mSv}$ and all the other TLDs (inside the barrier) had less than $1 \mathrm{mSv}(\mathrm{p}<0.001)$. In the post hoc analysis, the difference between TLD1 and others showed a statistical significance; however, there were no significant differences between the TLDs inside the barrier.

Conclusion Our mobile shield barrier was useful to reduce the radiation exposure of medical personnel during ERCP.

\section{INTRODUCTION}

Endoscopic retrograde cholangiopancreatography (ERCP) and its related procedures
Strengths and limitations of this study

- The newly designed mobile shield was easy to apply and dose not interfere with the endoscopic retrograde cholangiopancreatography (ERCP) procedure.

- The newly designed mobile shield was shown to significantly reduce the occupational dose to the endoscopist.

- The study period was relatively short (9 months) and the number of ERCP procedures was not very large.

- Comparisons of the radiation dose were performed only between the inside and outside of the mobile shield barrier and an independent control group was not established.

- The cumulative radiation dose was measured once every 3 months, without measuring the radiation dose for each ERCP procedure.

inevitably use ionising radiation for imaging of the bile duct and pancreatic duct during the procedure, which poses a potential risk of radiation exposure of medical staff and patients. ${ }^{1}$ Exposure of the human body to ionising radiation can result in damage to tissues and organs, and even with low levels of exposure may cause health problems, depending on the characteristics of each tissue. $^{2}$ Also, ionising radiation can cause genetic instability of cells, leading to cancer. ${ }^{3}$ The patient gains direct benefit from the procedure and is exposed to radiation only few times, whereas the medical staff are repeatedly exposed to radiation; therefore, more attention must be given to radiation protection for medical staff. To minimise the radiation exposure to patients and medical staff, the as low as reasonably achievable (ALARA) principle should be strictly followed and continuous monitoring of radiation exposure is required. ${ }^{4}$ The International Commission on Radiological Protection 


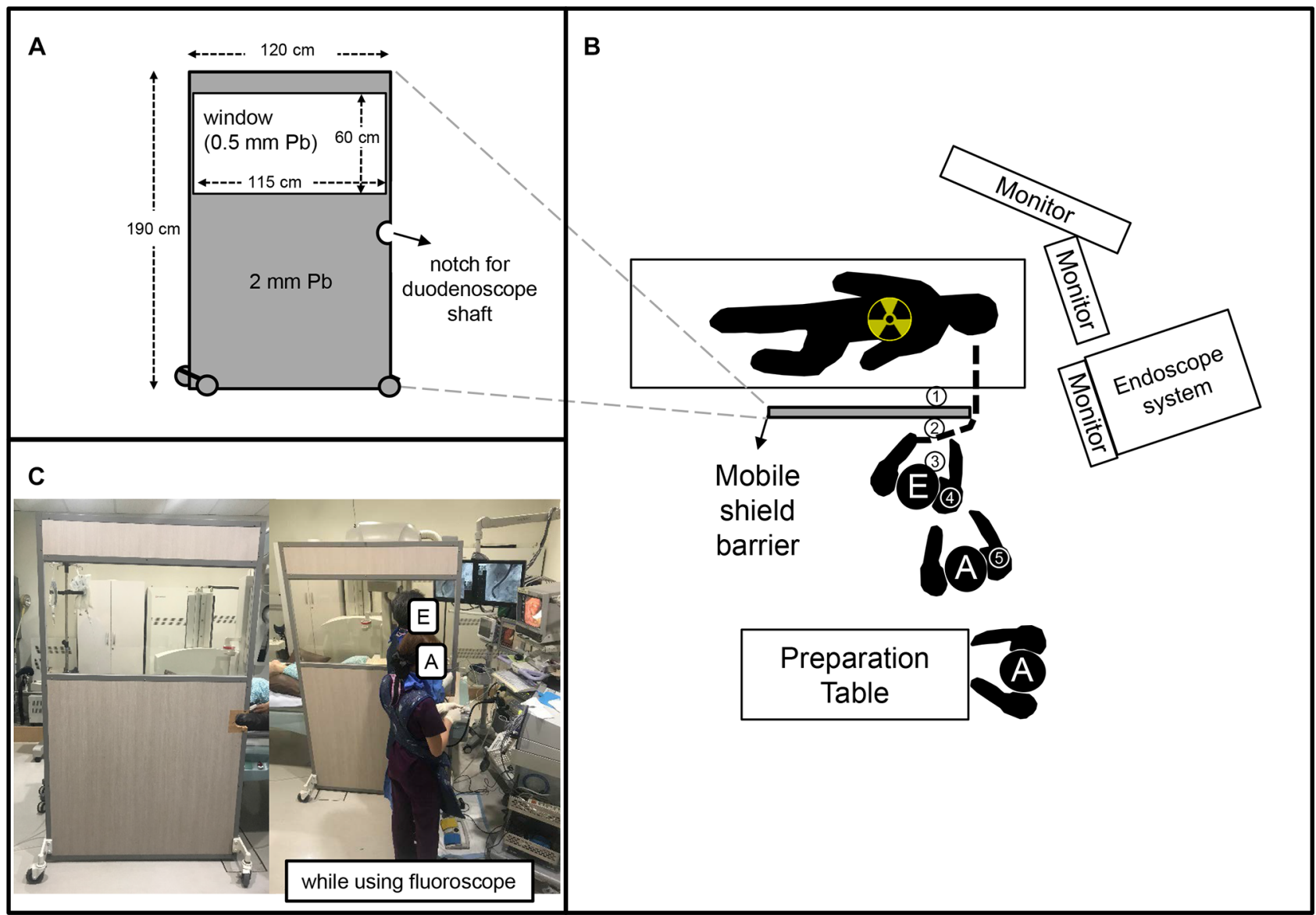

Figure 1 Endoscopic retrograde cholangiopancreatography (ERCP) room and mobile shield barrier. (A) Size and shape of mobile shield barrier. (B) Arrangement of fluoroscopy tube, table, endoscopic instruments and mobile shield barrier in the ERCP room. Locations of thermoluminescence dosimetry badges are indicated by circled numbers. TLD1, surface of the patient 's side of the mobile shield bairrer at the level of the medical staff's neck; TLD2, the medical staff's side of the mobile shield barrier at the level of the medical staff's neck; TLD3, on the outer surface of thyroid shield of endoscopist; TLD4, inside the protective apron at the level of the chest of endoscopist; TLD5, inside the protective apron at the level of the chest of endoscopist and that of the main assistant. (C) Photo of ERCP room and mobile shield barrier. A, assistant; E, endoscopist.

(ICRP) recommends a maximum safe limit for the effective dose of $20 \mathrm{mSv} /$ year (averaged over a defined 5-year period with no single year exceeding $50 \mathrm{mSv}$ ) for the whole body as well as for the eye, ${ }^{5}$ and the Institute of Nuclear Safety of the Republic of Korea also applies this recommendation for the radiation dose limit for occupational exposure in planned exposure situations.

There are several factors that affect the radiation exposure of medical staff during ERCP, one of which is the use of personal protective equipment and radiation protection shields. ${ }^{6}$ However, use of these protection devices are often overlooked due to lack of awareness of radiation hazards and the discomfort of using protective devices. According to a survey conducted in the Republic of Korea in 2011, only $52.5 \%$ of endoscopists responded that they always wore thyroid shield, and $26.9 \%$ of them rarely or never wore it. Moreover, only $14 \%$ wore lead glasses during the procedure and $69 \%$ never wore it and the usage rates of mobile shields or lead curtains were only $14 \%$ and $24 \%$, respectively. ${ }^{7}$ This propensity had not improved remarkably when a similar survey was conducted again in $2013 .{ }^{8}$ It would be possible to reduce this tendency by creating shielding barriers that are easy to use and have excellent protection capabilities. Therefore, a mobile shield barrier was designed that could be placed between the patient and the medical staff while the fluoroscopy is being employed. The mobile barrier had the ability to shield the entire body of the medical staff during ERCP. The aim of this study was to verify the effectiveness of our mobile shield barrier.

\section{MATERIALS AND METHODS \\ Study design}

This prospective quasi-experimental study was conducted in a secondary referral hospital which performs about 250 therapeutic ERCPs annually. The study period was between October 2016 and June 2017 and all the patients were over 18 years of age. Information including patient demographics, indications for ERCP, fluoroscopy time and number of digital radiographs was recorded at the time of the procedure. During the study period, radiation exposure doses to inner and outer surface of mobile 
shield barrier and medical staff in the ERCP room were measured at every therapeutic ERCP procedures.

\section{Endoscopic retrograde cholangiopancreatography}

All procedures were performed by using a Sonialvision Safire 17 fluoroscopy system (Shimadzu, Japan) which is an over-couch X-ray system comprising a digital table (ZS-100i, Shimadzu, Japan, width: $76.5 \mathrm{~cm}$, height: $235 \mathrm{~cm}$ ) and a high voltage X-ray generator (UD150BC40, Shimadzu, Japan, 80kW) installed in 2011. The fluoroscopy mode was set as pulsed fluoroscopy with a rate of 30 frames per second. Fluoroscopy time was displayed on the monitor of the fluoroscopy controller. The entire ERCP procedure was performed under fluoroscopic guidance using a standard side-view duodenoscope (TJF240, Olympus, Tokyo, Japan). One experienced endoscopist (BKS) performed all ERCP procedures and two assistants participated in each ERCP procedure. A total of four assistants participated alternately during the study period. There was no additional lead shielding in our ERCP room.

\section{Mobile shield barrier}

The mobile shield barrier was a custom-made $2 \mathrm{~mm} \mathrm{~Pb}$ shield plate (width: $120 \mathrm{~cm}$, height: $190 \mathrm{~cm}$ ) with a 0.5 $\mathrm{mm} \mathrm{Pb}$ window (width: $115 \mathrm{~cm}$, height: $60 \mathrm{~cm}$ ) on the upper part. Four wheels were attached to the bottom to allow for easy moving. In order to facilitate the duodenoscope manipulation, a notch through which the shaft of the endoscope can be inserted was made on the side of the barrier. This mobile shield barrier was placed between patient and the medical staff, including the endoscopist and the assisting nurse while the fluoroscopy was employed (figure 1). While not using the fluoroscopy, the mobile shield barrier was moved slightly to the left as not to interfere with the duodenoscope manipulation and is located at the patient's waist level. Each medical staff member wore a lead wrap-around protective apron $(0.35 \mathrm{~mm} \mathrm{~Pb})$, a thyroid shield (lead collar, $0.35 \mathrm{~mm} \mathrm{~Pb}$ ) and lead goggles $(0.75 \mathrm{~mm} \mathrm{~Pb})$.

\section{Outcome measurement}

The radiation exposure doses were measured by personal thermoluminescence dosimetry (TLD) badges (InLight Quixel, Hanil Nuclear Co., Republic of Korea) and were changed and reported every 3 months according to the Regulations for Safety Management of Diagnostic Radiation of the National Dose Registry, a part of the Korea Centers for Disease Control and Prevention.

TLD badges were attached to the surface of the patient's side (TLD1) and the medical staff's side (TLD2) of the mobile shield barrier at the level of the medical staff's neck. TLD3 was attached on the outer surface of thyroid shield of endoscopist, and TLD4 and TLD5 were placed inside the protective apron at the level of the chest of endoscopist and that of the main assistant. The primary outcome of the study was the radiation dose measured by the TLD badge. TLD1 and TLD2 are almost in the same position, but TLD1 is closer to the X-ray generator by about $1 \mathrm{~cm}$ due to the thickness of the mobile shield barrier.

\section{Statistical analysis}

Data are shown as the number (\%) for categorical variables and the mean $( \pm \mathrm{SD})$ for continuous variables. To compare the characteristics of the study groups, the $\chi^{2}$ test or Fisher's exact test was used for categorical variables and the student's t-test was used for the continuous variables to compare two groups. We used one-way analysis of variance, followed by a post hoc analysis using pairwise comparisons with Bonferroni adjustment to compare three or more groups, where appropriate. Double-sided

Table 1 Patient and procedural characteristics

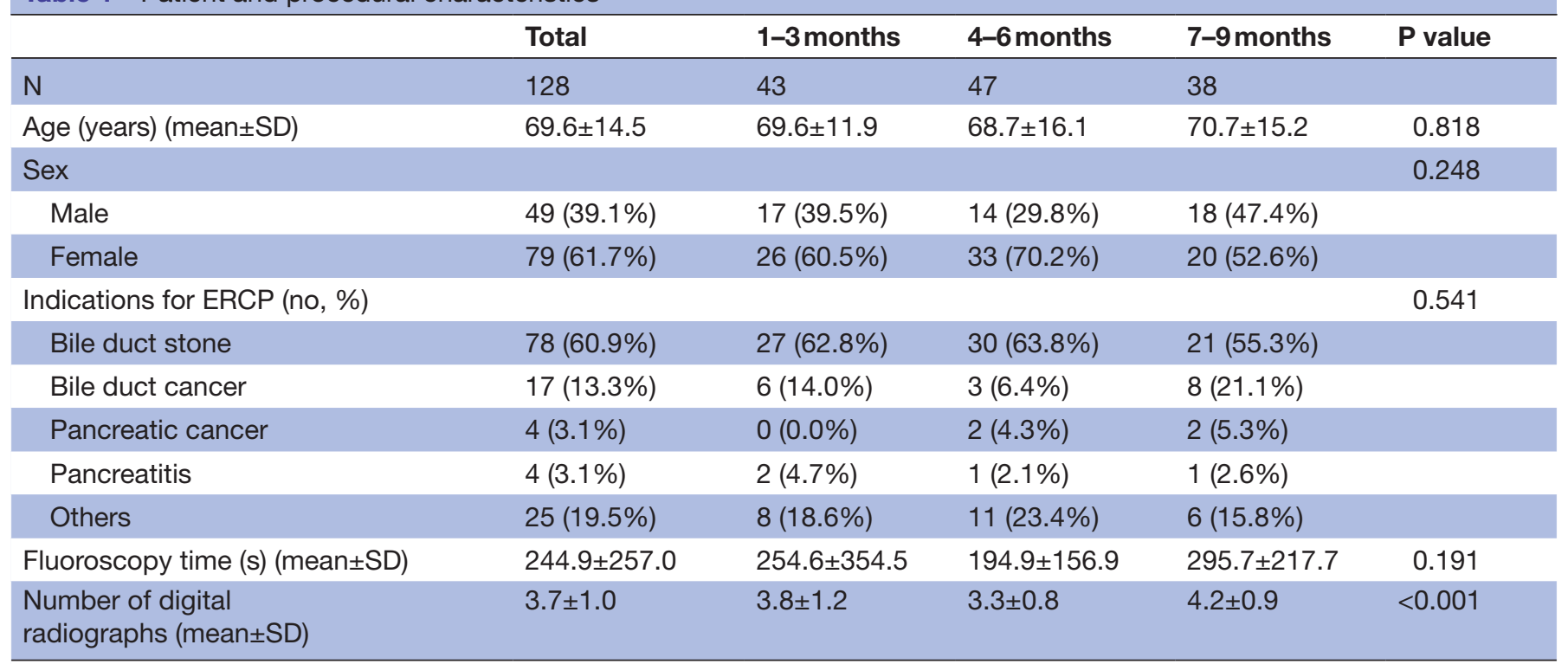

ERCP, endoscopic retrograde cholangiopancreatography. 
Table 2 Radiation exposure

\begin{tabular}{llll}
\hline & $\mathbf{1 - 3}$ months & 4-6 months & 7-9 months \\
\hline Number of ERCP procedure & 43 & 47 & 38 \\
\hline Cumulative fluoroscopy time & 10949 & 9160 & 5966 \\
\hline Cumulative number of digital radiographs & 165 & 153 & 158 \\
\hline Radiation dose (TLD1) (mSv) - barrier surface, patient's side & 30.69 & 25.89 & 0.25 \\
\hline Radiation dose (TLD2) (mSv) - barrier surface, medical staff's side & 1.50 & 0.16 & 0.22 \\
Radiation dose (TLD3) (mSv) - on the thyroid shield & 0.34 & 0.12 & 0.15 \\
\hline Radiation dose (TLD4) (mSv) - inside the lead apron, endoscopist & 0.33 & 0.10 & 0.08 \\
\hline Radiation dose (TLD5) (mSv) -inside the lead apron, nurse & 0.14 & 0.09 \\
\hline
\end{tabular}

ERCP, endoscopic retrograde cholangiopancreatography; TLD, thermoluminescence dosimetry.

$\mathrm{p}$ values of $<0.05$ were considered statistically significant. All statistical analyses were conducted using the $\mathrm{R}$ software ( $\mathrm{R}$ for Windows V.3.5.1; The R Foundation for Statistical Computing, Vienna, Austria).

\section{Patient and public involvement}

This research was done without patient involvement. Patients were not invited to comment on the study design and were not consulted to develop patient relevant outcomes or interpret the results. Patients were not invited to contribute to the writing or editing of this document for readability or accuracy.

\section{RESULTS}

\section{Patients and procedure details}

Patient characteristics and procedure details are described in table 1 .

During the study period, a total of 128 ERCP procedures were performed. The mean age of patients was $69.6 \pm 14.5$ years. The indication for ERCP was mostly choledocholithiasis $(60.9 \%)$. The mean fluoroscopy time per procedure was $244.9 \pm 257.0 \mathrm{~s}$ and the mean number

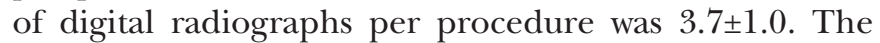
patient age, sex and indications for ERCP were not significantly different in each 3-month period.

\section{Cumulative radiation exposure}

The cumulative radiation exposure of each 3-month period is presented in table 2 .

The cumulative fluoroscopy time and digital radiograph number as well as the TLD doses were highest in the first 3 -month period. The mean TLD result of each location is presented in figure 2. TLD1 (outside the barrier) had a mean radiation dose of $26.85 \pm 3.47 \mathrm{mSv}$ and all the rest of TLDs (inside the barrier) were less than $1 \mathrm{mSv}(\mathrm{p}<0.001)$. In the post hoc analysis, the difference between TLD1 and the others showed statistical significance $(p<0.001)$; however, there were no significant differences between the TLDs inside the barrier $(p=1.000)$.

\section{DISCUSSION}

Several methods are used for protecting medical personnel from radiation during ERCP, and personal protective equipment is one of the methods. ${ }^{6}$ Personal protective equipment, however, does not cover the entire body; moreover, its heavyweight can cause musculoskeletal disorders and can sometimes be disregarded due to discomfort. ${ }^{6}$ In this study, we showed that the amount of radiation reaching the medical staff can be drastically reduced by using a mobile shield barrier. Moreover, from the inside the mobile shield barrier, there was

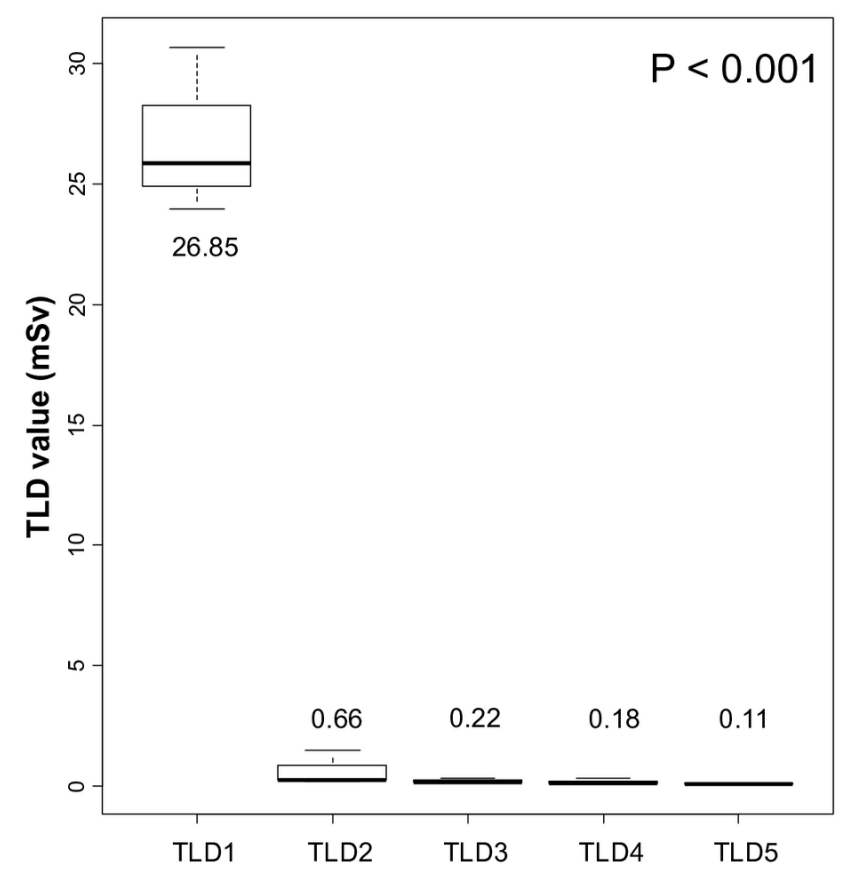

P-values of pairwise comparisons using Bonferroni adjustment

TLD 1 vs. TLD 2, TLD 1 vs. TLD 3, TLD 1 vs. TLD 4, TLD 1 vs. TLD 5; $P<0.001$ TLD 2 vs. TLD 3, TLD 2 vs. TLD 4, TLD 2 vs. TLD 5; $P=1.000$

TLD 3 vs. TLD 4, TLD 3 vs. TLD 5; $P=1.000$

TLD 4 vs. TLD $5 ; P=1.000$

Figure 2 Box plot of thermoluminescence dosimetry value at different locations. Each number represents the mean value. TLD, thermoluminescence dosimetry. 
no significant difference between the radiation doses reaching the inside and outside of the personal protective equipment.

The idea of using a protective shield to protect medical staff from radiation during ERCP has been around for a long time. In 1996, Chen et at attempted to reduce the radiation exposure of medical personnel by using a $0.5 \mathrm{~mm}$ lead acrylic shield that hangs from the ceiling and could be placed between the patient and the endoscopist, which significantly reduced the radiation exposure of the endoscopist from $2.5 \mathrm{mR}$ to $0.27 \mathrm{mR}$ per procedure. In 2002, Johlin $e t \mathrm{al}^{10}$ used a phantom model to demonstrate that a curtain of beads fashioned as a shield could reduce the radiation exposure of medical staff during ERCP. More recently, in 2011, Kim et $\mathrm{l}^{11}$ used a curtain-shaped protective shield composed of seven movable lead plates to reduce radiation. Several other studies have attempted to attach lead shields directly to X-ray tubes ${ }^{12-14}$ or image intensifiers. ${ }^{15}$ The above-mentioned studies commonly used a method of hanging a radiation protective shield from above, similar to a curtain. In contrast, our protective shield is set on the floor which has less weight-related constraints; thus, we are able to use a shield that is bigger than that used in previous studies to cover a wider range. Although no direct comparison with other shielding devices has been performed, the theoretical advantage of a bigger size of our mobile shield barrier is that it will be able to shield scattered waves from more diverse angles and ranges. Another point to consider is that manipulation of the duodenoscope may be interrupted by the shielding barrier. This problem was solved by putting wheels on the bottom of the shield barrier to allow easy movement of the shield and a small notch was incorporated on the side to acquire space for movement of the duodenoscope shaft. The shield barrier was placed between the patient and medical staff only when using the fluoroscopy; during most of the time that the duodenoscope was manipulated, the shield barrier was moved slightly to one side so as not to interfere with the duodenoscope manipulation. In addition, ancillary effects are expected to reduce unnecessary fluoroscopy time.

The amount of radiation the medical staff receives over a period is affected by various factors. The physical environment of the ERCP unit, the distance between medical staff and the radiation source or the patient, the type of X-ray system (over-couch, under-couch, or mobile C-arm unit), the fluoroscopy parameters (use of pulsed rather than continuous fluoroscopy, use of lower frame rates of fluoroscopy, number of radiographs, use of collimation of X-ray beam, use of low magnification) and the use of protective equipment can affect the radiation dose. ${ }^{616-19}$ Moreover, the fluoroscopy time is determined by important factors such as the difficulty of the procedure, ${ }^{20}{ }^{21}$ the proficiency level of the endoscopist and the assistant, ${ }^{22}$ education and awareness regarding radiation protection, ${ }^{23}{ }^{24}$ and the number of ERCP procedures during the period. Hence, the different scenarios at each institution and those of the ERCP units should be taken into account when comparing the degree of radiation exposure for each institution. Our institution is using an over-couch X-ray system, in which the amount of radiation received by medical staff is known to be higher than under-couch X-ray systems, especially on the thyroid gland and eyes, which is vulnerable to radiation. ${ }^{6}$ Therefore, the radiation protection of medical staff should be more thorough.

The fluoroscopy time per procedure in our study is approximately $4 \mathrm{~min}$ which is not significantly different from the fluoroscopy times of previous studies (5.32$14.5 \mathrm{~min}) .{ }^{12} 1516$ The actual radiation dose received by medical personnel may differ from the radiation dose measured by the TLD; nonetheless, the radiation dose outside the mobile shield barrier exceeded $80 \mathrm{mSv}$ only in 9 months. According to the results of our study alone, the amount of radiation exposure in areas without protective equipment is more than $150 \mathrm{mSv}$ which exceeding the ICRP limits ${ }^{5}$ when we perform 250 ERCPs per year without shielding barriers. As this level is high, a more aggressive protection strategy is warranted, and our mobile shield barrier could be a possible solution by reducing the radiation exposure to less than $4 \mathrm{mSv} /$ year which far below the ICRP limit. ${ }^{5}$

Our study had a few limitations. Our study was conducted for a relatively short period of 9 months and the number of ERCPs was not very large. In addition, only the radiation dose inside and outside the mobile shield barrier was compared without setting the independent control group without a mobile shield barrier or with different type of shield. The total procedure time and complication rate were not investigated and comparisons of those between with and without mobile shield barrier were not performed. However, we showed reduction of the radiation dose by approximately $1 / 40$ using the mobile shield barrier, which demonstrates remarkable efficacy and not only just a statistical difference. Moreover, the radiation doses between the TLDs inside the mobile shield barrier were not significantly different, and this can help reduce the role of personal protective equipment. In the case of the total procedure time, considering that the mobile shield barrier was only used during the fluoroscopy was working, the impact on the total operation time was not considered to be significant, and fluoroscopy time did not differ much from other studies. Perhaps the time to move the mobile shield barrier to the left or right may be added, but it takes less than $5 \mathrm{~s}$. During the study period, there were no major complications such as clinically significant bleeding or perforation. There were several mild postERCP pancreatitis occurred, but no severe pancreatitis was occurred. Considering that the main cause of pancreatitis is pancreatic duct injury and oedema of papilla, most of them will occur while attempting ductal cannulation which is not the mobile shield barrier was using. ${ }^{25}$ Therefore, we think that the impact of mobile shield barrier to the post-ERCP pancreatitis would be minimal.

Compared with the previous protective shields, the improvement of our mobile shield barrier is that it could 
have a bigger size because it is set on the floor. It covers wider range and does not interfere with the procedure. And because it is not attached to wall, ceiling, fluoroscopy tube or table, it is easy to install and easy to remove. In conclusion, radiation exposure in inevitable during ERCP and this can cause various health problems in medical personnel. It is essential to lower the radiation exposure by as much as possible and various protective equipment or devices should be used appropriately. The newly designed mobile shield barrier was found to be extremely effective in reducing radiation exposure and could be one of the options for protecting medical personnel from radiation exposure during ERCP. It may be used for other fluoroscopic procedures, such as endoscopic pyloric stenting or colonic stenting and further research is needed.

Contributors BKS contributed to the concept and design of the study. He also drafted the initial manuscript. KHC critically reviewed the research protocol and contributed to analysing of data and writing of the manuscript. YSP and SBA contributed to the data interpretation and critically revised the manuscript. All authors were involved in editing the manuscript. All authors read and approved the final manuscript.

Funding The authors have not declared a specific grant for this research from any funding agency in the public, commercial or not-for-profit sectors.

Competing interests None declared.

Patient consent for publication Not required.

Ethics approval The study protocol was approved by the institutional review board of Eulji General Hospital (protocol number: EMCIRB 2017-07-013).

Provenance and peer review Not commissioned; externally peer reviewed.

Data sharing statement All available data can be obtained from the corresponding author.

Open access This is an open access article distributed in accordance with the Creative Commons Attribution Non Commercial (CC BY-NC 4.0) license, which permits others to distribute, remix, adapt, build upon this work non-commercially, and license their derivative works on different terms, provided the original work is properly cited, appropriate credit is given, any changes made indicated, and the use is non-commercial. See: http://creativecommons.org/licenses/by-nc/4.0/.

\section{REFERENCES}

1. Tsapaki V, Paraskeva KD, Mathou N, et al. Patient and endoscopist radiation doses during ERCP procedures. Radiat Prot Dosimetry 2011;147:111-3.

2. Stewart FA, Akleyev AV, Hauer-Jensen M, et al. ICRP publication 118: ICRP statement on tissue reactions and early and late effects of radiation in normal tissues and organs--threshold doses for tissue reactions in a radiation protection context. Ann ICRP 2012;41:1-322.

3. Richardson DB, Cardis E, Daniels RD, et al. Risk of cancer from occupational exposure to ionising radiation: retrospective cohort study of workers in France, the United Kingdom, and the United States (INWORKS). BMJ 2015;351:h5359.

4. Campbell N, Sparrow K, Fortier M, et al. Practical radiation safety and protection for the endoscopist during ERCP. Gastrointest Endosc 2002;55:552-7.

5. Rehani MM, Ciraj-Bjelac O, Vañó E, et al. ICRP Publication 117. Radiological protection in fluoroscopically guided procedures performed outside the imaging department. Ann ICRP 2010;40:1-102.

6. Dumonceau JM, Garcia-Fernandez FJ, Verdun FR, et al. Radiation protection in digestive endoscopy: European Society of Digestive Endoscopy (ESGE) guideline. Endoscopy 2012;44:408-24.

7. Son BK, Lee KT, Kim JS, et al. Lack of radiation protection for endoscopists performing endoscopic retrograde cholangiopancreatography. Korean J Gastroenterol 2011;58:93-9.

8. Shin JM, Lee TH, Park SH, et al. A survey of the radiation exposure protection of health care providers during endoscopic retrograde cholangiopancreatography in Korea. Gut Liver 2013;7:100-5.

9. Chen MY, Van Swearingen FL, Mitchell R, et al. Radiation exposure during ERCP: effect of a protective shield. Gastrointest Endosc 1996;43:1-5.

10. Johlin FC, Pelsang RE, Greenleaf M. Phantom study to determine radiation exposure to medical personnel involved in ERCP fluoroscopy and its reduction through equipment and behavior modifications. Am J Gastroenterol 2002;97:893-7.

11. Kim YJ, Cho KB, Kim ES, et al. [Efficacy of a self-designed protective lead shield in reduction of radiation exposure dose during endoscopic retrograde cholangiopancreatography]. Korean $J$ Gastroenterol 2011;57:28-33.

12. Minami T, Sasaki T, Serikawa M, et al. Occupational radiation exposure during endoscopic retrograde cholangiopancreatography and usefulness of radiation protective curtains. Gastroenterol Res Pract 2014;2014:1-5.

13. Mori $\mathrm{H}$, Koshida $\mathrm{K}$, Ishigamori $\mathrm{O}$, et al. A novel removable shield attached to $\mathrm{C}$-arm units against scattered X-rays from a patient's side. Eur Radiol 2014;24:1794-9.

14. Morishima Y, Chida K, Meguro T. Effectiveness of additional lead shielding to protect staff from scattering radiation during endoscopic retrograde cholangiopancreatography procedures. J Radiat Res 2018;59:225-32.

15. Muniraj T, Aslanian HR, Laine L, et al. A double-blind, randomized, sham-controlled trial of the effect of a radiation-attenuating drape on radiation exposure to endoscopy staff during ERCP. Am J Gastroenterol 2015;110:690-6.

16. Jowhari F, Hopman WM, Hookey L. A simple ergonomic measure reduces fluoroscopy time during ERCP: a multivariate analysis. Endosc Int Open 2017;5:E172-78.

17. Churrango G, Deutsch JK, Dinneen HS, et al. Minimizing radiation exposure during ERCP by avoiding live or continuous fluoroscopy. $J$ Clin Gastroenterol 2015;49:e96-100.

18. Tsapaki V, Paraskeva KD, Tsalafoutas IA, et al. The impact of X-ray unit type used for endoscopic retrograde cholangiopancreatography procedures on patient doses. Radiat Prot Dosimetry 2016;171:503-8.

19. Boland GW, Murphy B, Arellano R, et al. Dose reduction in gastrointestinal and genitourinary fluoroscopy: use of grid-controlled pulsed fluoroscopy. AJR Am J Roentgenol 2000;175:1453-7.

20. Saukko E, Grönroos JM, Salminen P, et al. Patient radiation dose and fluoroscopy time during ERCP: a single-center, retrospective study of influencing factors. Scand J Gastroenterol 2018;53:495-504.

21. Hayashi S, Nishida T, Matsubara T, et al. Radiation exposure dose and influencing factors during endoscopic retrograde cholangiopancreatography. PLoS One 2018;13:e0207539.

22. Liao C, Thosani N, Kothari S, et al. Radiation exposure to patients during ERCP is significantly higher with low-volume endoscopists. Gastrointest Endosc 2015;81:391-8.

23. Barakat MT, Thosani NC, Huang RJ, et al. Effects of a brief educational program on optimization of fluoroscopy to minimize radiation exposure during endoscopic retrograde cholangiopancreatography. Clin Gastroenterol Hepatol 2018;16:550-7.

24. Zeng $\mathrm{HZ}$, Liu $\mathrm{Q}$, Chen $\mathrm{HL}$, et al. A pilot single-center prospective randomized trial to assess the short-term effect of a flashing warning light on reducing fluoroscopy time and radiation exposure during ERCP. Gastrointest Endosc 2018;88:261-6.

25. Tryliskyy Y, Bryce GJ. Post-ERCP pancreatitis: pathophysiology, early identification and risk stratification. Adv Clin Exp Med 2018;27:149-54. 